Research Article

\section{Consequence of birth year, type, sex, season and flock on birth weight trait of Kajli sheep}

Farmanullah ${ }^{1 a *}$, Khalid Javed ${ }^{2}$, Mohammad Salim³, Momen Khan $^{4}$, Sajid Ali ${ }^{5}$, Talpur Hira Sajjad ${ }^{6}$, Muhammad Altaf Hussain ${ }^{1}$, Ihsanullah Kakar', Inayat Ur Rehman ${ }^{7}$, Asma Babar $^{1}$, Sajjad Ahmad ${ }^{1}$, Bhunesh ${ }^{1}$ and Sami Ullah Khan ${ }^{8}$

${ }^{1}$ Faculty of Veterinary and Animal Sciences, Lasbela University of Agriculture, Water and Marine Sciences, Uthal, Balochistan, Pakistan

${ }^{2}$ Faculty of Animal Production and Technology, The University of Veterinary and Animal Sciences, Lahore, Punjab, Pakistan

${ }^{3}$ Forestry and Wildlife Management Department, University of Haripur KPK, Pakistan

${ }^{4}$ Livestock and Dairy Development Department, Khyber Pakhtunkhwa, Pakistan

${ }^{5}$ Departments of Horticulture, University of Haripur, Khyber Pakhtunkhwa, Pakistan

${ }^{6}$ Department of Animal Breeding and Genetics, Sindh Agriculture University, Tandojam

${ }^{7}$ School of Marxism, China University of Geo Sciences (Wuhan), Hongshan District Region Wuhan, P.R.China

${ }^{8}$ Laboratory of Microbiology and Immunology, College of Veterinary Medicine, Institute of Preventive Veterinary Medicine, Sichuan Agricultural University, Chengdu, China

${ }^{1}$ Key Laboratory of Agricultural Animal Genetics, Breeding and Reproduction, Education Ministry of China, College of Animal Sciences and Technology, Huazhong Agricultural University, Wuhan 430070,

Peoples Republic of China

\section{More Information}

*Address for Correspondence: Dr. Farmanullah, Faculty of Veterinary and Animal Sciences, Lasbela University of Agriculture, Water and Marine Sciences, Uthal, Balochistan, Pakistan, Tel: 92313-0342-0333-9231209; Email: farman.vas@luawms.edu.pk; farman_aup@yahoo.com

Submitted: 03 July 2020

Approved: 08 August 2020

Published: 10 August 2020

How to cite this article: Farmanullah, Javed K, Salim M, Khan M, Ali S, et al. Consequence of birth year, type, sex, season and flock on birth weight trait of Kajli sheep. Insights Vet Sci. 2020; 4: 035-041.

DOI: 10.29328/journal.ivs.1001024

ORCiD: orcid.org/0000-0003-1163-5004

Copyright: (c) 2020 Farmanullah, et al. This is an open access article distributed under the Creative Commons Attribution License, which permits unrestricted use, distribution, and reproduction in any medium, provided the original work is properly cited.

Keywords: Birth weight; Breeding values; Genetic and phenotypic Parameters; Heritability; Kajli sheep

T) Check for updates

OPEN ACCESS

\title{
Abstract
}

The liaison of birth weight to neonatal and mature vigor is especially given important if have the acquaintance of factors distressing in birth weight. Unbiased Best linear prediction of breeding values was estimated from pedigree birth weight records of 13715 Kajli sheep of livestock Experiment Station Khizerabad born 1994 to 2010, and Livestock Experimental Station, Khushab. Data records were statistically analyzed by means of using computer programmed Mixed Model Harvey's Least Squares and Maximum Likelihood. An animal model was used for heritability estimation following Maximum Likelihood procedure. Estimates of birth weight heritability in Kajli sheep were $0.05 \pm 0.019$. The estimated breeding values of both forms for males, females, and sire were calculated with significant variation. Both farms data were analyzed by using an animal model program. The squares mean slightest for weight at birth $(\mathrm{kg})$, remained $4.13 \pm 0.01 \mathrm{~kg}$. In addition, birth of the year, the birth of type, flock and sex significantly affects the $(p<0.001)$ trait of birth weight. The domino effect of the current study has rational implications not only for sheep husbandry nevertheless as well as for amplified acquaintance of parameters which drastically persuade deviation of weight in birth as weight in birth has become itself noteworthy forecaster of anon fitness outcomes. These results showed the decreasing genetic and static phenotypic at birth weight. It is likely that there are complex interactions between genetics and environmental factors of parental, placental and fetal origin. Birth weight is highly influenced trait by maternal nutrition, genes, care, management, climate, seasonal variation and type of birth.

\section{Introduction}

Epidemiological studies estimate that about $25 \%$ of birth weight variances are due to environmental influences and $38 \%-80 \%$ is attributable to genetic influences [1.2]. There is substantial inconsistency in the estimates of the fetal and parental mechanism of these heritable influences from
$18 \%$ to $69.4 \%$ and from $3 \%$ to $20 \%$ conflict of birth weight, correspondingly. The sheep size of birth determined plays the role of significant by genetic and environmental factors. Main importance and supply of meat and wool is sheep in most of the developing countries. Kajli sheep, the biggest and most productive sheep breed, is well-known for its juicy mutton quality. In attendance is a spacious miscellany 
in an assortment of fabrication persona of this breed which suggests an enormous span for the perfection of recital traits.

This miscellany in concert traits might be owed to some genetic besides green effects. Formulating breeding plan and selection efficient strategies, knowledge of essential traits is required as repeatability, heritability and correlations among these traits [3]. An increase in the profitability of lamb production is a function of reducing input costs and increasing production output. The genetic parameters vary with site, period of time, extent of statistics establishes and the model castoff intended for their approximation. The pragmatic feat of every single animal in every mannerism is present the consequence of inheritance the aforementioned gets from equally parentages in addition the milieu happening which the situation exists raised up. Flush once a stab be situated through in the direction of endow with consistent surroundings, in attendance be there quiet fortuitous besides mysterious ecological differences amongst faunae. Such arbitrary ecological influences in that way cause alterations in the countenance of thriftily imperative characters.

Amongst these ecological aspects, environment and periodic alterations happening diverse years distress the creation of the entire herd; whereas gender, kind of natal, stage in addition weight distress the distinct act [4]. Hence, approximation of the extent of all such influences turn out to be very perilous for developing well-organized in addition to actual breeding strategies for their upgrading [4]. Solitary of the traits of financial magnitude in sheep is birth weight. The assortment of recital traits of sheep may be ascribed to several genetic and nongenetic factors. Birth weight of lambs has an imperative role in a good sheep production [5].

Weight at birth has a conventional imperfect reflection in sheep breeding programs, but it is a trait of latent fiscal consequence due to its possessions on pre-weaning growth and hence, it increases the economic success of producing massacre animals [6]. The domino effect of the current study has rational implications is neither limited to small ruminants management, Nevertheless as well as amplified acquaintance of parameters drastically persuade deviation of birth weight turn out to be itself noteworthy forecaster of anon fitness results, comprehension of pre-delivery conditions and parameters effects discrepancy weight at birth is of key consequence of stare to abrupt (offspring) and huge phrase physical condition and practicability $[7,8]$. Now the agricultural commerce, facts in the peripheral, convenient features that must a demeanor on the animate weight at phrase are essential in term of a farming budget.

Tentatively, in species of all mammalian, in attendance is a finest of weight at the birth happening of unsophisticated innate liberation may arise, besides newborn endurance are maximized delimited through an array of competence, besides the deviation from this in birth weight finest but newborns stay alive towards procreative epoch. Evidently here is a sturdy hereditary constituent secretarial for several of the discrepancy in weight at birth as excesses afar this array will, in excess of period, be designated out squat weight at birth stands allied by augmented newborn transience, lofty weight at birth through intricate toil (dystocia), and tender demise [9]. Nevertheless in humanoid motherly heaviness (an ecological factor) accounted aimed at individual $12 \%$ of the disparity in weight at birth [10].

Signifying there are various further aspects sway ultimate weight by the side of tenure. in a specious of these polytocous, such by means of the sheep, nearby are a integer of eminent impacts that radically impinge on newborn intensification then consequently ultimate weight at birth, comprising litter size abridged entity weight at birth by way of escalating litter size, in addition to gender of the progeny genders [11-13]. Using gaze at toward motherly sustenance inducing weight at birth happening the sheep, to a great extent in rank is vacant but infrequent discrepancies crop up, most likely due to cram differences flanked by type of sheep mock-up extent, clarity of optimal or $100 \%$ requisite $[11,12,14-18]$.

Additionally, with meticulous multilevel modeling, the enormity of revolutionizing in weight at birth through adaptations happening motherly sustenance throughout precise times of growth, i.e. untimely opposed to belatedly maturation, possibly will stay evaluated with a momentous extent of arithmetic clout. The aforementioned be present hypothesized that tardy, by way of contrasting near initial, dietetic ingestion extensively sound possessions weight at birth happening the sheep as this reproduces the interlude of utmost utter fetal escalation [16]. Parturition moreover touches fetal growing the most primitive born existence welllit than the consequent happening homo sapiens $[7,19]$, and the sheep $[20,21]$ nevertheless whether this consequence lasts by way of rising parity (i.e. $>2$ pregnancies) remains not unambiguous. This is situated trendy sequence is incredibly imperative in the farming commerce for a paradigm to be acquainted with the digit of seasons a ewe relics maximally dynamic in relations of lamb weight at birth and as soon as (i.e. after by what means numerous pregnancies) that efficiency debilities. Although it is contemplation that first pregnancy foliage an enduring uterine functional indentation that effects the jiffy gestation, it be present, not notorious whether a sheep that involvements an ensuing bleak spell possibly will have amendments in the direction of auxiliary triumphant gestations happening stipulations of lamb weight at birth. Objective of this study was to evaluate the performance of a purebred flock of Kajli sheep maintained at two ecologies in Pakistan. The research Project was thus planned on Kajli sheep to measure the effects of known environmental and genetic factors which tend towards incomprehensible the inherited variances amongst animals for birth weight. 


\section{Materials and methods}

Statistics records on the performance of 13715, lambing by ewes, 3342; sired 128; produced in Kajli sheep from 1994 to 2010 were employed in the present study. Pedigree and data records performance of Kajli sheep in livestock experiment station khizarabad during 1994 to 2010 collected, Sargodha $\left(32.0286^{\circ} \mathrm{N}, 72.5205^{\circ} \mathrm{E}\right)$ and Livestock Experimental Station, Khushab $\left(32.3054^{\circ} \mathrm{N}, 72.3482^{\circ} \mathrm{E}\right)$ were utilized in the present investigation. Recorded information pertaining to the identity of individuals, dams, and sires, birth date, type of birth, sex, weight at birth, weaning weight, and yearling weight were castoff to assessment hereditary and phenotypic parameters of several concert traits. The recital trait examined in the current study was included birth weight. Lambs were produced mainly during the spring season because generally once a year the ewes were bred in the autumn season. Autumn season was the choice for lambing and the ewes were mated in the subsequent spring season if the ewes which were not bred during the autumn season. Mostly rams used in breeding were farm produced, but for genetic heterogeneity to provide outside introduction had also been practiced. Rams for breeding 10-15 per season were selected normally.

Meat production improvement had mainly focused and a little attention had been paid to wool traits in the overall breeding plan of major thrust. Statistically, data were analyzed on birth weight trait performance to estimate the source of variation in the trait under study for various genetic magnitudes. The effect of the environmental factors viz, Time and term of birth, birth type, gender of lamb, weaning age. Proceeding weight at birth remained evaluated, solitary standard and inclusive records were painstaking for analyses. Numerous edits as the outliers from the data were removed before starting the analysis. Only for analysis, the complete and normal records were reviewed. Worksheet MS Excel was used only for facts ingress. Animal model individual fitting restricted maximum procedure likelihood (Patterson and Thompson) [22] was used for the genetic parameters via heritability estimation. The criterion convergence (function values of variance- 2 Log Likelihood) of genetic parameters various was $1 \times 10^{-8}$.

\section{Estimation of heritability}

The heritability mathematical model estimation as follows was assumed: (Model 1)

$Y_{i j k}=\mu+F_{i}+A j+e_{i j k}$ Where,

$Y_{i j k}=$ Particular trait Measurement

$\mu=$ Mean Population

$F_{i=}$ The initial analysis observed fixed effects to be significant

$A j=$ Influence of $\mathrm{jth}$ animal genetic additive random by mean zero and modification $\sigma 2$ $e_{i j k}=$ Variance $\sigma 2 \mathrm{e}$ and mean zero with random error

The following formula was used for heritability calculation:

Heritability $\left(\mathrm{h}^{2}\right)=\sigma 2 \mathrm{~A} / \sigma 2 \mathrm{P}$

\section{Genetic trends and breeding values estimation}

Best linear unbiased predication (BLUP) procedures [23] were used only for the estimation birth performance trait of the animals breeding values. As a byproduct, the DFREML set of computer programs too creates predictable breeding standards. The model having fixed effect only births of year, the estimated breeding values were fitted in a fixed effect. Breeding values least squares solutions to depict the genetic trend was drawn against the year of birth. Phenotypic trends were established by plotting different phenotypic values against the year of birth.

\section{Statistical analysis}

Statistics on birth weight presentation traits stood evaluated to appraise the sway of diverse ecological dynamics (Non-genetic causes of discrepancy) such as time and period of birth, gender of lamb, age of the dam, kind of natal, weaning stage, on birth weight. The year of birth or lambing was divided into two seasons and the definition of the season of lambing was; spring, from January to June and autumn, from July to December.

The mathematical model assumed was: $\mathrm{Yij}=\mu+F_{i}+e_{i j}$ (Model: 2) Where,

$Y_{i j}=$ Measurement of a particular trait

$\mu=$ Population mean

$F_{i}=$ The effect of all fixed effects with the restriction that $\sum F_{i}=0$

$\mathrm{e}_{i j}=$ The random error associated with each observation.

The Harvey's Least Squares Maximum Likelihood Mixed Model (LSMLMW) supercomputer software was used for all these analyses [24].

\section{Results}

\section{Heritability estimates}

The heritable sonata of a population can be willful by keeping in mind the next of kin import of heredity and ecological factors upsetting the recital of folks in that populace. The most frequently used parameters are heritability and genetic correlation. Figures were tested for the inference of heritability of birth weight. The estimated heritability of birth weight was attained at $0.054 \pm 0.019$.

\section{Estimation of breeding values}

Estimated breeding values for birth weight are shown in 
table 1. Birth weight values breeding estimated for farm A were from -0.205 to $0.164 \mathrm{Kg}$ in males and ranged from -0.149 to $0.180 \mathrm{Kg}$ in females, respectively. Whereas, farm B, values fluctuated from -0.157 to $0.173 \mathrm{Kg}$ in males and from -0.148 to $0.145 \mathrm{Kg}$ in females respectively. The breeding values estimated for sire in farm A and farm B are given in table 1. Birth weight breeding values ranged in farm A -0.169 to $0.164 \mathrm{~kg}$. Birth weight breeding values ranged in farm B -0.157 to 0.173 $(\mathrm{Kg})$ respectively.

\section{Environmental factors are affecting performance trait}

In flock single born lamb percentage was approximately high and it was 84\%. The percentage of twinning born was $15.73 \%$. Almost males and females sex ratio was 49:51. While birth weight $(\mathrm{Kg})$ trait means values were $(4.13 \pm 0.01)$ in Kajli sheep. Influence evaluates variance analysis for a birth year, the birth of season, type of birth and sex are assumed in table 2 . Significantly the weight at birth varied $(p<0.01)$

Table 1

\begin{tabular}{l|l|l|l|l|l|l} 
Traits & No. EBVs for male No. EBVs for female No. EBVs for sires
\end{tabular}

\begin{tabular}{|l|l|l|l|l|l|l|}
\hline Birth weight & 2984 & -0.205 to 0.164 & 6771 & -0.149 to 0.180 & 105 & -0.169 to 0.164 \\
\hline
\end{tabular} Farm A \begin{tabular}{|c|c|c|c|c|c|c|}
$\begin{array}{c}\text { Birth weight } \\
\text { Farm B }\end{array}$ & 176 & -0.157 to 0.173 & 624 & -0.148 to 0.145 & 18 & -0.157 to 0.173 \\
\hline
\end{tabular}

Farm A: Livestock Experiment Station Khizarabad, Sargodha.

Farm B: Livestock Experimental Station, Khushab.

Table 2: Least squares mean $( \pm \mathrm{SE})$ for birth weight $(\mathrm{Kg})$ in Kajli sheep.

\begin{tabular}{|c|c|c|c|}
\hline Year of Birth & No of observation & LSM \pm S-E & Significance \\
\hline 1994 & 834 & $4.25 \pm 0.02$ & \\
\hline 1995 & 1325 & $4.26 \pm 0.01$ & \\
\hline 1996 & 1068 & $4.23 \pm 0.02$ & $p<0.001$ \\
\hline 1997 & 948 & $4.19 \pm 0.02$ & \\
\hline 1998 & 866 & $3.87 \pm 0.02$ & \\
\hline 199 & 876 & $4.20 \pm 0.02$ & \\
\hline 2000 & 948 & $4.11 \pm 0.02$ & \\
\hline 2001 & 779 & $4.27 \pm 0.02$ & \\
\hline 2002 & 656 & $3.72 \pm 0.02$ & \\
\hline 2003 & 497 & $3.70 \pm 0.03$ & \\
\hline 2004 & 638 & $4.10 \pm 0.02$ & \\
\hline 2005 & 709 & $4.20 \pm 0.02$ & \\
\hline 2006 & 707 & $4.26 \pm 0.02$ & \\
\hline 2007 & 752 & $4.12 \pm 0.02$ & \\
\hline 2008 & 789 & $4.29 \pm 0.02$ & \\
\hline 2009 & 830 & $4.23 \pm 0.02$ & \\
\hline 2010 & 493 & $4.19 \pm 0.03$ & \\
\hline \multicolumn{4}{|l|}{ Season of Birth } \\
\hline Spring & 8766 & $4.14 \pm 0.03$ & $p>0.05$ \\
\hline Autumn & 4949 & $4.13 \pm 0.01$ & \\
\hline \multicolumn{4}{|l|}{ Sex } \\
\hline Male & 6724 & $4.43 \pm 0.01$ & $p<0.001$ \\
\hline Female & 6991 & $3.83 \pm 0.01$ & \\
\hline \multicolumn{4}{|l|}{ Type of Birth } \\
\hline Single & 11557 & $4.60 \pm 0.00$ & $p<0.001$ \\
\hline Twin & 2158 & $3.67 \pm 0.01$ & \\
\hline \multicolumn{4}{|l|}{ Flock } \\
\hline Farm A & 12537 & $3.96 \pm 0.00$ & $p<0.001$ \\
\hline Farm B & 1178 & $4.34 \pm 0.02$ & \\
\hline
\end{tabular}

Foot Notes: EBVs: Estimated Breeding Values; LSM: Least Squares Mean;

SE: Standard Eroor; Single: One; Kid Born; Twin: Two Kids Born due to sex, season, years, flock and type of birth. The interface between sex and type of birth showed non-significant. The least squares mean, for weight at birth was $4.23 \pm 0.03(\mathrm{Kg})$ during 1994 and showed a fluctuating trend up to the year 2010.

The least squares means in birth weight remained almost constant for the year 1994 to 2010 ranging from (4.10 \pm 0.02 to $4.27 \pm 0.02$ ) except for the years 1998, 2002 and 2003 in which least squares means in birth weight showed slight decrease in the values as $(3.87 \pm 0.02,3.72 \pm 0.02)$ and $(3.70 \pm 0.03)$, respectively. However, the difference in the least squares means in birth weight was found for both the flocks viz, A and B. The flock B showed higher least squares mean in birth weight than $A$ which were $4.34 \pm 0.02$ and $3.96 \pm 0.00$, respectively.

\section{Discussion}

\section{Heritability estimates for birth weight}

Weight at birth heritability was low at $0.054 \pm 0.019$. The results are consistency with the result reported by [25-30]. Lambing records data 1285 ewes of Lohi sheep kept at Bahadurnagar production livestock research institute 1960-1990 time of period. He estimates the heritability for birth weight which is a bit higher than the present study and reported $0.10 \pm 0.02$. The results of [29] who analyzed performance data on Hissardale sheep maintained at Livestock Experiment Station Jahangirabad and reported the heritability estimate of body weight at birth as $0.08 \pm 0.02$ were in close settlement with the conclusion of the current study.

On the other hand, many researchers have also reported heritability estimates higher than the present study [31-36]. Qureshi, [37] reported heritability for birth weight as $0.14 \pm 0.05$, which was estimated at livestock experiment station Khushab and Khizerabad lambing data 16470, of 5311 ewes. Ali, et al. [27] estimate heritability from the Rambouillet sheep data analysis kept in livestock Experiment station Jaba district Mansehra (KP) Pakistan, as $0.07 \pm 0.02$, the above results were in conformity with the results reported in this present study $(0.054 \pm 0.019)$. The differences in diverse information may be owing to differences in genotypes, the bulk of facts set, and the technique of estimation or edit criteria, and may be used for a different model study approach.

\section{Estimation of breeding values}

Genetic trends for birth weight in Kajli sheep showed a decreasing trend and the phenotypic trend was fluctuating, whereas, the genetic and phenotypic trend intended for weight at birth exhibited a fluctuating tendency. The overall trend was static and this was similar to the results presented by Hussain [38] reported that breeding value for rams ranged from -0.447 to 0.216 for birth weight. The overall genetic trend was static. There were fluctuations among the least square means for estimated breeding values. Whereas, conclusions of [39] 
and [40] did not coincide with the present study. Estimates of genetic parameters and pragmatic genetic trends established that discriminating procreation can lead to momentous genetic perfection in Menz sheep. The consequences of the present cram showed the low estimates of genetic improvement in the production trait which suggested that selection was ineffective to bring about the desired change.

It also indicated that the animal selection could not be adept in the appropriate track in addition some sort of unsystematic mating had been practiced. The genetic trend for all performance traits indicated that the breeding program in the present flock throughout the epoch under study did not prove to be efficient. Attention to breed type becomes harmful once it is motivated without fixing the standard of fabrication. In this way, animals overhead the middling of actual efficacy were superfluous for the reason that they did not assure to breed sort in substances which remained of diminutive or no monetary magnitude [41]. The genetic disparity amid the folks is an additional factor which determines the tempo of genetic perfection that can be proficient through assortment. With a squat ballpark figure of heritability, the anticipated expansion of the traits mentioned in the present study is to a large extent fewer through assortment as compared to what could be achieved by other ecological changes.

This low estimate of genetic differences among the individuals was seen as an important factor that rendered selection ineffective [42]. The culling in the flock under exploration was not according to the recommended level and frequently those animals flabby for breeding, repeaters or under par was inclined off. The culling on the root of low live weight was hardly ever practiced. It could be anecdotal from the current study that in the charisma of these factors, the selection persisted unproductive toward carry about the anticipated variations over the last 17 years of the period. It suggested that better feeding and management will improve the position. As the unique genetic and phenotypic groups trends for birth weight are shown in the following Figures 1 to 6.

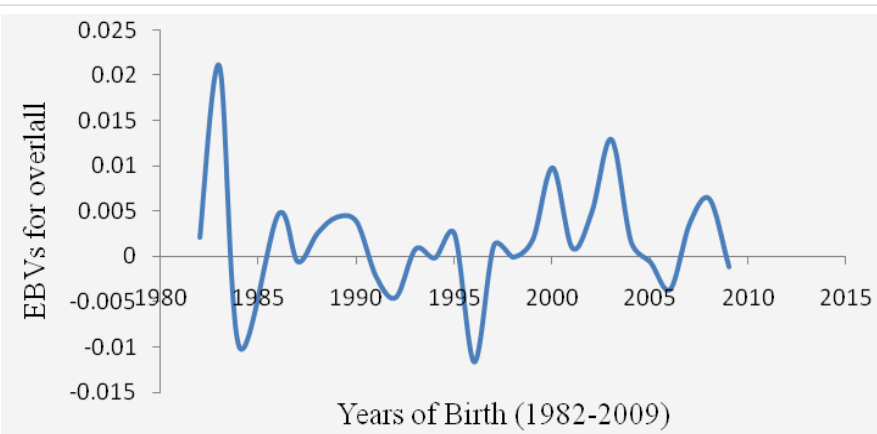

Figure 1: The Genetic trend for birth weight in Kajli female sheep during 1982-2009 at Farm A ranged from -0.149 to 0.180 . The overall trend was static.

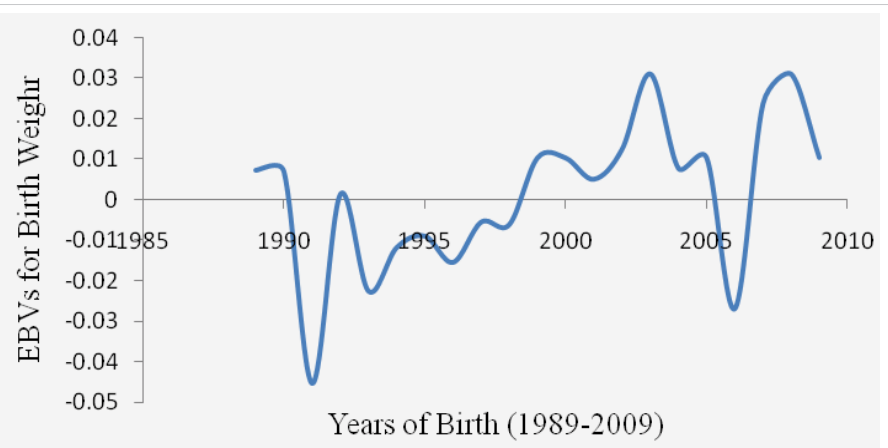

Figure 2: Genetic Trend for Birth Weight in Kajli Sheep during 1989-2009 of Male in Farm A ranged from -0.205 to 0.164 .the genetic trend for birth weight in Kajli sheep showed a decreasing trend.

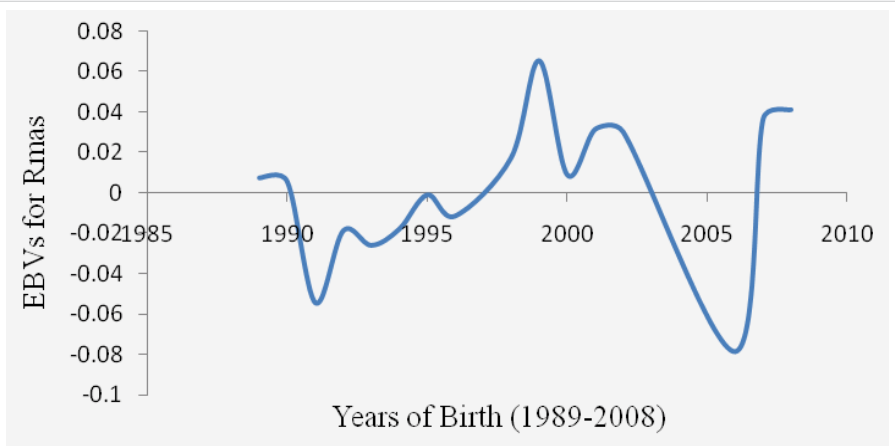

Figure 3: Genetic Trend for Birth Weight of ram during 1989-2008 at farm A ranged from -0.169 to 0.164 . There were wide fluctuations among the least square means for estimated breeding values.

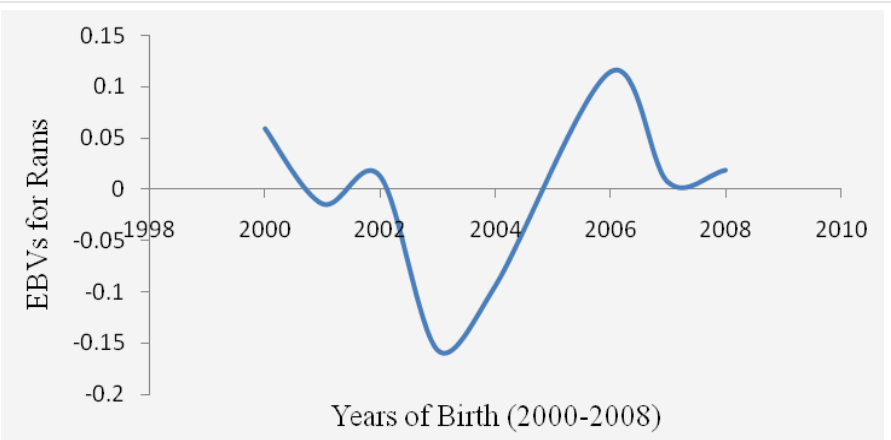

Figure 4: Genetic Trend for Birth Weight of ram during 1989-2008 at farm A ranged from -0.169 to 0.164 . There were wide fluctuations among the least square means for estimated breeding values.

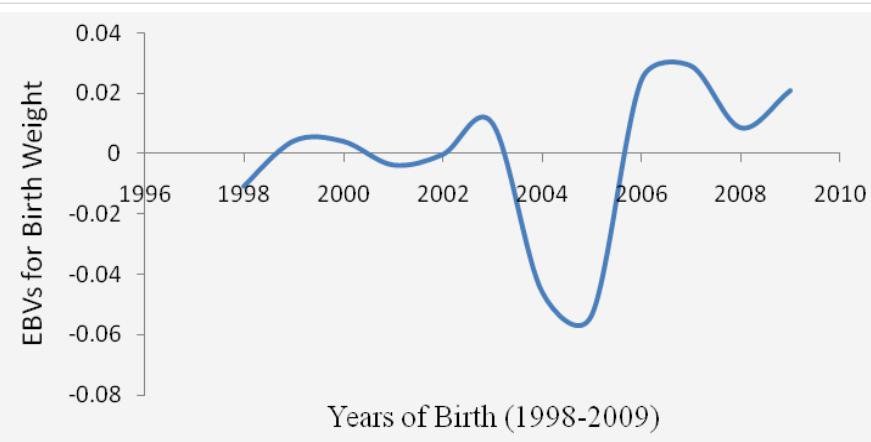

Figure 5: Genetic Trend for Birth Weight in Kajli Sheep during 1998-2009 at Farm B ranged from -0.148 to 0.145 .it showed that the low estimates of genetic Improvement in the Productive traits suggested that selection was ineffective to bring about the desirable change. 


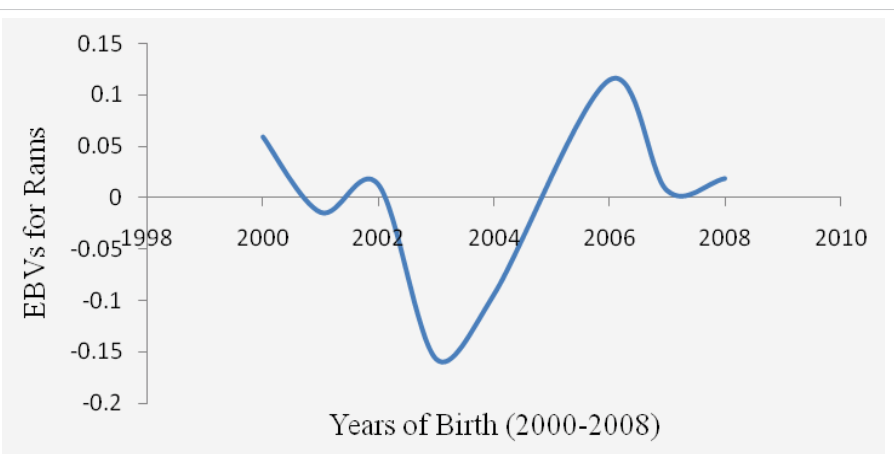

Figure 6: The Genetic trend for birth weight of ram during 2000-2008 at farm B ranged from -0.157 to 0.173 .due to practice of some sort of random mating and selection of Animals. Attention to bred type becomes harmful when it is focused without Fixing the standard of production.

\section{Environmental factors affecting birth weight}

The significant sway of year, gender of lamb born, kind of birth and flock on birth weight obtained in the current study is in concord with many researchers $[4,27,30,38,43-45]$ stated that time and term of lambing, gender of lamb, kind of birth, besides stage of dam remained significant bases of disparity for lamb birth weights in Bharat Merino sheep. Akhtar, et al. [45] indicated that the birth weight in Hissardale was drastically pretentious by means of year, season, birth type, gender, besides time of life of the dam. The findings of [31] are completely in covenant by means of the contemporary study who described the significant impact of station, year of birth, sex and birth type $(p<0.01)$. Furthermore, similar to the present study, the influence of term on weight at birth remained recorded non-significant. The disparity of birth weight in lambs as diverse years reflected the echelon of the executive, some green sound effects like, temperature and humidity as well as the availability of feed. Noticeably, the side by side of managing is assured in the direction of fluctuate conferring on the way to the services in the farm executive, his coordination of harvest farming, approaches, and passion of discarding, and his competence in direction of the farm labor as well as accessibility of monetary assets [46].

Theexecution offarming musthavebeen tainted recurrently and its effects were reflected in the performance traits over the years. The weight at birth of lambs correspondingly varied by means of gender, and sort of birth. The lambs born single are weightier than the manifold lambs born as they have better opportunities trendy the uterus of their dams to grow as associated to manifold lambs born. Similarly, the male lambs remained weightier at weight at birth as the gestation period of males are slightly longer as compared to females [25]. Numerous reports in literature also indicated that single born lambs, as well as the male lambs, were heavier than multiple births and females. As, in the present study the birth weight of a male was heavier than female ( $4.44 \pm 0.01$ and $3.88 \pm 0.01$, respectively), similarly the single born had heavier birth weight than twins (4.63 \pm 0.12 and $3.69 \pm 0.19$, respectively). The maximum lambing was reported in spring season $(83.04 \%)$ while $4.86 \%$ were reported in autumn and only $11.92 \%$ were reported in offseasons. This indicates the seasonality of breeding in sheep under different climatic conditions.

\section{Conclusion}

Solitary of the traits of financial magnitude in sheep is birth weight. Lambs weight at birth play an imperative role in sheep first rate production. Birth weight varied significantly due to years, season, sex, type of birth and flock. These results showed the decreasing genetic and static phenotypic at birth weight. It is likely that there are complex interactions between genetics and environmental factors of parental, placental and fetal origin. Data showed non- significant interaction between sex and type of birth. The genetic trends for birth weight in Kajli sheep showed decreasing trend and phenotypic trend was fluctuating. The variation in body weight due to year, sex, and season of birth were significant. Whereas effect of flock and type of birth were non- significant. Birth weight is highly influenced trait by maternal nutrition, genes, care, management, climate, seasonal variation and type of birth. Factors affecting birth weight of Kajli Sheep at two ecologies in Pakistan. Therefore, Formulating breeding plan and selection efficient strategies, knowledge of essential traits is required.

\section{Acknowledgement}

I express sincere thanks to Dr. Allah Ditta Sial farm superintendent. Thanks to Dr. Nisar Ahmed Warraich, (Veterinary Officer) who provided access to data and other facilities at the farm. I am also very appreciative to the co-authors for their critical and technical improvement of our manuscript.

\section{References}

1. Yoon MH. Genetic and Environmental Influences on Birthweight in a Sample of Korean Twins. J Korean Med Sci. 2005; 20: 355-360. PubMed: https://www.ncbi.nlm.nih.gov/pmc/articles/PMC2782186/

2. Workalemahu T, Katherine L. Grantz, J. Grewal, C. Zhang, M. et al. Genetic and Environmental Influences on Fetal Growth Vary during Sensitive Periods in Pregnancy. Sci Rep. 2018; 8: 7274.

3. Usman T, Suhail SM, Zhang X, Guo G, Ullah I, et al. Effects of nongenetic factors on age at first conception and calving interval in Holstein cattle under subtropical conditions. Indi J Ani Sci. 2014; 84: 45-49.

4. Kuthu ZH, Javed K, Babar ME, Sattar A, Abdullah M. Environmenta Effects on Growth Traits of Teddy Goats. J Ani PI Sci. 2013. 23: 450-462.

5. Petrovic MP, Muslic DR, Petrovic VC, Maksimovic N. Influence of environmental factors on birth weight variability of indigenous Serbian breeds of sheep. Afri J Biot. 2011; 10: 4673-4676.

6. Al-Shorepy SA. Estimates of genetic parameters for direct and maternal effects on birth weight of local sheep in the United Arab Emirates. Sm Rumi Res. 2001; 39: 219-224.

7. Cogswell ME, Yip R. The influence of fetal and maternal factors on the distribution of birthweight. Semi Perinat. 1995; 19: 222-240.

PubMed: https://pubmed.ncbi.nlm.nih.gov/7570074/

8. Godfrey KM, Barker DJ. Fetal programming and adult health. Pub Hea Nut. 2001; 4: 611-624.

PubMed: https://pubmed.ncbi.nlm.nih.gov/11683554/ 
9. Alexander $\mathrm{G}$. Birth weight of lambs: influences and consequences. In Size at Birth. 2014; 215-245.

PubMed: https://www.ncbi.nlm.nih.gov/pmc/articles/PMC1994721/

10. Brooks AA, Johnson MR, Steer PJ, Pawson ME, Abdalla HI. Birth weight: nature or nurture? Earl Hum Devel. 1995; 42: 29-35.

PubMed: https://pubmed.ncbi.nlm.nih.gov/7671843/

11. Wallace LR. The growth of lambs before and after birth in relation to the level of nutrition. J Agri Sci. 1948; 38: 243-302.

12. Robinson JJ. The influence of maternal nutrition on ovine fetal growth. Proc Nutri Soci. 1977; 36: 9-16.

13. Black JL. Growth and development of lambs. In Sheep Production. 1983. 21-58.

14. Russel AJ. Relationships between energy intake and productivity in hill sheep. Proc Nutri Soci. 1971; 30: 197-204.

15. Russel AJ, Foot JZ. The effect of level of nutrition at two stages of pregnancy on the performance of primiparous ewes. Proc Nutri Soci. 1973; 32: 27A-28A.

PubMed: https://pubmed.ncbi.nlm.nih.gov/4760782/

16. Mellor DJ, Matheson IC. Daily changes in the curved crown-rump length of individual sheep fetuses during the last 60 days of pregnancy and effects of different levels of maternal nutrition. Quarterly J Exp Phy Cog Medi Sci. 1979; 64: 119-131.

PubMed: https://pubmed.ncbi.nlm.nih.gov/256627/

17. Wallace UO, Aitken JM, R.P, Cheyne MA. Nutrient partitioning and fetal growth 1 in rapidly growing adolescent ewes. J Rep Fert. 1996; 107: 183-190.

18. Heasman L, Brameld J, Mostvn A, Budge H, Dawson J, et al. Materna nutrient restriction during early to mid-gestation alters the relationship between insulin-like growth factor I and bodyweight at term in fetal sheep. Rep Fert Dev. 2000; 12: 345-350.

19. Ong KK, PreeceMA, Emmett PM, Ahmed ML, Dunger DM. Size at birth and early childhood growth in relation to maternal smoking, parity and infant breast-feeding: longitudinal birth cohort study and analysis. Ped Res. 2002; 52: 863-867.

PubMed: https://pubmed.ncbi.nlm.nih.gov/12438662/

20. Bradford GE. The role of maternal effects in animal breeding. VII. Maternal effects in sheep. J Ani Sci. 1972; 35: 1324-1334.

21. Bradford GE, Taylor CS, Quirke JF, Hart R. An egg transfer study of litter size, birth weight, and lamb survival. Ani Prod. 1974; 18: 249-263.

22. Patterson HD, Thompson R. Recovery of inter-block information when block sizes are unequal. Biom. 1971; 58: 545-554.

23. Henderson CR. Sire evaluation and genetic trends. In Animal Breeding Genetics. Symposium of American Society of Animal Science and American Dairy Science Association, Champaign, Illinois. 1973; 10-41.

24. Harvey WR. User's Guide for LSMLMW (PC version) Mixed Mode Least Square and Maximum Likelihood Computer Program, Ohio State Uni Ohio Uni Sta. 2000.

25. Baber ME. Genetic and phenotypic parameters of some performance characteristics of Lohi sheep. Ph.D. Thesis, University of Agricultural Faisalabad, Pakistan. 1994

26. Neser FWC, Erasmus GJ, Wyk JBV. Genetic parameter estimates for pre-weaning weight traits in Dorper sheep. Sm Rumi Res. 2001; 40: 197-202.

27. Ali S, Hussain A, Akhtar $P$, Younas M, Khan MA. Relationship of birth weight of lambs with age of ewes at service in Rambouillet sheep. Pak Vet J. 2006; 26: 187-189.

28. Behzadi B, Shahroudi MRFE, Vleck LDV. Estimates of genetic parameters for growth traits in Kermani sheep. Ani Breed Genet. 2007; 124: $296-301$.

29. Akhtar P, Ali S, Hussain A, Mirza MA, Mustafa MI, et al. Heritability estimates of post-weaning performance traits in Hissardale sheep in Pakistan. Turk J Vet Anim Sci. 2008; 32: 275-279.

30. Javed K, Iram A, Abdullah M, Sattar MA, Akhtar M. Genetic trends for some productive traits of Lohi sheep in Pakistan. Pak J Sci. 2013; 65: $492-495$

31. Qureshi MA, Babar ME, Ali A. Environmental and Genetic factors influencing Performance traits of Kajli sheep in Pakistan. Pak J Zoo. 2010; 42: 339-343.

32. Fadili El, Michaux MC, Detilleux J, Leroy PL. Genetic parameters for growth traits of the Moroccan Timahdit breed of sheep. Sm Rumi Res. 2000; 37: 203-208.

33. Mousa E, Monzaly H, Shaat I, Ashmawy A. Factors affecting birth and weaning weights of native farafra Lambs in upper Egypt. Egy J Sh G Sci. 2013; 8: 1- 10.

34. Hanford KJ, Vleck LDV, Snowder. Estimates of genetic parameters and genetic change for reproduction, weight, and wool characteristics of Targhee Sheep. J Ani Sci. 2003; 81: 630-640.

35. Miraei ASR, Seyedalian SAR, Shahrbabak MM. Variance components and heritabilities for body weight traits in Sangsari sheep, using univariate and multivariate animal models. Sm Rum Res. 2007; 73: 109-114

36. Vatankhah M, Talebi MA. Heritability estimates and correlations between production and reproductive traits in Lori-Bakhtiari sheep in Iran. So. Afri J Ani Sci. 2008; 38: 110-118.

37. Qureshi A. Genetic and environmental components of various performance traits of Kajli sheep in Pakistan. Ph.D. Thesis, Uni. of Agri. Faisal. Pak. 1996.

38. Hussain A. Genetic evaluation of Thalli sheep. Ph.D. Thesis. Uni Agri. Faisal, Pak. 2006

39. Gizaw S, Lemma S, Komen H, Arendonk JAMV. Estimates of genetic parameters and genetic trends for live weight and fleece traits in Menz sheep. Sm Rumi Res. 2007; 70: 145-153.

40. Bosso NA, Cisse MF, Vander EH, Waaij, Fall A, et al. Genetic and phenotypic parameters of body weight in West African Dwarf goat and Djallonké sheep. Sm Rumi Res. 2007; 67: 271-278.

41. Javed $\mathrm{K}$, Abdullah $\mathrm{M}$, Khan MA. Estimation of breeding value and genetic trends in Sahiwal cattle in Pakistan. J Ani PI Sci. 2002; 12: 1-6.

42. Javed K. Genetic and phenotypic aspects of some performance traits in a purebred herd of Sahiwal cattle in Pakistan. Ph.D. Thesis, Uni. of Agri. Faisal. Pak. 1999.

43. Dixit SP, Dhillon JS, Singh G. Genetic and non-genetic parameter estimates for growth traits of Bharat Merino lambs. Sm Rumi Res. 2001; 42: 101-104.

44. Akhtar P, Ahmad Z, Mohiuddin G, Ali S, Javed K. Environmental factors affecting pre-weaning growth traits of Hissardale sheep in Pakistan. Pak V J. 2001; 21: 17-21.

45. Babar ME, Ahmad Z, Nadeem A, Yaqoob M. Environmental factors affecting birth weight in Lohi sheep. Pak Vet J. 2004; 24: 5-8.

46. Akhtar P. Genetic and phenotypic parameters of some performance characteristics of Hissardale sheep. Ph.D. Thesis, University of Agricultural, Faisalabad, Pakistan. 1996.

47. Hanford KJ, Vleck LDV, Snowder. Estimates of genetic parameters and genetic change for reproduction, weight, and wool characteristics of Columbia Sheep. J Ani Sci. 2002; 80: 3086-3098.

PubMed: https://pubmed.ncbi.nlm.nih.gov/12542148/

48. Prakash VL, Prince LL, Gowane GR, Arora AL. The estimation of covariance components and genetic parameters for growth traits and Kleiber ratios in Malpura sheep of India. Sm Rumi Res. 2012; 108: 54-58.

49. Meyer K. User's notes of DFREML Set of Computer Programmes Version 3.0.00a. 1997. 